21 Vijayan P, Mukundan P, Sukhoor AA, et al. Epidemic poliomyelitis. Indian Pediatr 1985: 22; 569-73.

22 Santhanakrishan BR, Deivanayagam N, Parthasarathy A, et al. Poliomyelitis in children. Indian foumal of Pediatrics 1987: 54: 755-58.

23 Pendey S, Alam B, Jhe SS, et al Polioparalysis. A critical review, fournal of Rehabilitation in Asia 1975: 20: 21-7.

24 Sancheti KH, Sahasrabudhe BG, Bhingare RK, Electricwala JT. Clinico-environmental profile of residual paralytic poliomyelitis. Indian Council of Medical Research Bulletin 1981; 2: 59-66.

25 Sahadeva KC, Gupta AC. Polio paralysis. Clinical observations and management report of 500 cases. fournal of Rehabition in Asia 1972, 13: 7-11.
26 Punatar BJ, Patel DA. Pattern of residual paralysis in poliomyelitis. Indian fournal of Orthopaedics 1971: 2; 174-8.

27 Johns TJ. Poliomyelitis in India. Prospects and problems in control. Rev Infect Dis 1984; 6 (suppl 2): 438-41.

28 Nicholas DD, Kratzer JM, Ofasu Ammah S, et al. Is poliomyelitis a serious problem in developing countres? The Dafna experience. BMf 1977, i: 1009-12.

29 Nwuga VCB, Odunowa T. Some clinical characteristics of children with paralytic poliomyelitis referred for physiotherapy. 7 Trop Med Hyg 1978, 81: 84-7.

30 Guyer B, Bisong AAE, Gould J, et al. Infections and paralytic Poliomyelitis in tropical Africa. Bull World Health Organ 1980: 58; 285-91.

\section{An 18th century trial}

Sir Austin Bradford Hill stated ${ }^{1}$ that the essence of any trial is comparison and gave the following quotation from the writings of James Lind $(1753)^{2}$ as an example of a classical experiment in the treatment of scurvy which makes clear this concept.

"On the 20th of May, 1747, I took twelve patients in the scurvy, on board the Salisbury at sea. Their cases were as similar as I could have them. They all in general had putrid gums, the spots and lassitude, with weakness of their knees. They lay together in one place, being a proper apartment for the sick in the fore-hold; and had one diet common to all, viz. water-gruel sweetened with sugar in the morning; fresh mutton-broth often times for dinner; at other times puddings, boiled biscuit with sugar etc. And for supper, barley and raisins, rice and currants, sago and wine, or the like. Two of these were ordered each a quart of cyder a day. Two others took twenty-five gutts of elixir vitriol three times a day, upon an empty stomach; using a gargle strongly acidulated with it for their mouths. Two others took two spoonfuls of vinegar three times a day, upon an empty stomach; having their gruels and their other food well acidulated with it, as also the gargle for their mouths. Two of the worst patients, with the tendons in the ham rigid (a symptom none of the rest had) were put under a course of sea-water. Of this they drank half a pint every day, and sometimes more or less as it operated, by way of gentle physic. Two others had each two oranges and one lemon given them every day. These they eat with greediness, at different times, upon an empty stomach. They continued but six days under this course, having consumed the quantity that could be spared. The two remaining patients, took the bigness of a nutmeg three times a day of an electuary recommended by a hospital-surgeon, made of garlic, mustard-seed, rad. raphan, balsam of Peru, and gum myrrh; using for common drink barley-water well acidulated with tamarinds; by a decoction of which, with the addition of cremor tartar, they were greatly purged three or four times during the course.

The consequence was, that the most sudden and visible good effects were perceived from the use of the oranges and lemons; one of those who had taken them, being at the end of six days fit for duty. The spots were not indeed at that time quite off his body, nor his gums sound; but without any other medicine, than a gargle of elixir vitriol, he became quite healthy before we came into Plymouth, which was on the 16 th June. The other was the best recovered of any in his condition; and being now deemed pretty well, was appointed nurse to the rest of the sick."

1 Hill AB. Statistical methods in clinical and preventive medicine. London: Livingstone, 1962.

2 Lind J. A treatise of the scurvy in three parts, containing an inquiry into the nature, causes and cure of that disease, together with a critical and chronological view of what has been published on the subject. Edinburgh: Sands, Murray, and Cochran, 1753. 